\title{
THE EYES OF THE NEEDLES: A SEQUENTIAL MODEL OF UNION ORGANIZING DRIVES, 1999-2004
}

\author{
JOHN-PAUL FERGUSON*
}

\begin{abstract}
This paper models three stages of the union organizing drive, using a new dataset covering more than 22,000 drives that took place between 1999 and 2004. The correlated sequential model tracks drives through all of their potential stages: holding an election, winning an election, and reaching first contracts. Only one-seventh of organizing drives that filed an election petition with the NLRB managed to reach a first contract within a year of certification. The model, which controls for the endogeneity of unfair labor practice (ULP) charges, finds that a ULP charge was associated with a $30 \%$ smaller cumulative chance of reaching such a contract. ULP charges had less effect on the votes cast than on the decision to hold an election and the ability to reach a first contract. A sequential model such as this one could be extended to test between some competing theories about the determinants of union organizing
\end{abstract}

$\mathbf{I}_{\mathrm{n}}$ ndustrial relations research has produced numerous studies of the conditions under which unions are formed and grow. In the United States and other countries with union-election regimes, this work has overwhelmingly focused on election results. Yet elections are but one step in a longer process rife with opportunities for success or failure. Since during an election it is the workers rather than the union (as an organization) or the employer who determine success or

*John-Paul Ferguson is a doctoral candidate at the Institute for Work and Employment Research, Sloan School of Management, Massachusetts Institute of Technology. He thanks Lotte Bailyn, Alex Bryson, Emilio J. Castilla, Roberto Fernandez, Elizabeth Kilpatrick, Thomas Kochan, Paul Osterman, and Chris Riddell for support and suggestions.

The raw data used in this paper are available from the National Labor Relations Board and the Federal Mediation and Conciliation Service. Copies of the computer programs used to construct and analyze this dataset can be obtained from the author at the Massachusetts Institute of Technology, Sloan School of Management, 50 Memorial Drive, E52-533, Cambridge, MA 02142; jpferg@mit.edu. failure, our theories of union formation have given more weight to things that shape individual preferences for unionization than to the influence of the organizational process. This paper incorporates elements of that organizational process by treating the election as only one of the needles' eyes through which workers must pass to join a union.

The focus on elections has stemmed in part from missing data for the other stages of the process. To date, nationally representative data have never been assembled to calculate the likelihood that an effort to unionize through the formal NLRB election procedure will reach its ultimate goal. This paper assembles the data to do so. Since employer resistance to unionization has long been a central topic of industrial relations research (Flanagan 2005; Freeman 2005), this paper examines how the presence of an unfair labor practice (ULP) charge affects the probability of reaching different stages of the organizing process. I use ULP charges by individuals or unions against the employer as the main independent variable for two reasons. First, they are an important indicator of the health of the industrial-rela- 
tions system. Second, despite the intuitive importance of ULP charges, prior work has found conflicting associations between them and representation election outcomes.

Organizing drives in the United States must clear more than one hurdle: through them, unionists must win the right to hold a representation election, win the election, and then negotiate a contract with the employer. By gathering data for each of these stages and estimating success in each stage separately, I am able to identify factors that affected whether elections were held, whether (and by what margin) an election resulted in a win for the union, and whether a first contract was reached after electoral victory. Not all factors affect success in all of these stages. An organizing drive need only fail in one stage to fail completely, however, so understanding when and why different factors impinge on success is important for any planning to improve the election process.

My ultimate goal in this paper is not to uncover all the determinants of organizing success at all stages of the process but rather to gather and present recent and nationally representative data on phases of the organizing process for which such data have not previously been available. The resulting analysis shows that at least some important determinants of union-organizing success, such as ULP charges, seem to matter more in the buildup to and aftermath of elections than in the voting itself. I calculate the cumulative likelihood of surviving an organizing campaign and then estimate the cumulative impact of a ULP charge. Finally, I offer some speculation about how a sequential approach could be used to extend research on union organizing.

\section{The Union Organizing Drive}

There are three ways to form a union under the National Labor Relations Act (NLRA). First, an employer and the employees' chosen representative can voluntarily negotiate a collective-bargaining agreement without informing the National Labor Relations Board (NLRB). Second, employees can vote for a union in a secret-ballot election that the NLRB certifies. Third, the NLRB can require an employer to bargain with a union when the board determines that actions by the employer have made it all but impossible for a free and fair secret-ballot election to take place. The third means has become extremely uncommon. The first means, socalled voluntary recognition, accounts for a growing share of organizing drives (Brudney 2005). Yet voluntary recognition is limited to cases in which the employer either does not oppose unionization or has agreed to it in the face of strong public pressures, such as corporate campaigns. Election is the procedure that is embedded in the law and that gives employees a way to organize even if the employer is opposed. It is the means with the widest scope and thus the best indicator of the health of the system as a whole.

For most employees, a union is a means to the end of changing the terms and conditions of work. That end requires a collective-bargaining agreement, or contract. In countries where such contracts are negotiated at the industry level, the adoption of contract terms can follow almost automatically from union recognition. In the United States, where most unions negotiate a contract with a single employer or even with a single establishment, the one need not follow the other: "Because a sizable number of employers refuse to accept unions even after an NLRB election and have the economic strength to resist union efforts, there is a leakage from elections to contracts" (Freeman and Medoff 1984). Thus, when the outcome of interest is a change in employment relations, the representation election is not a final outcome. Instead, it is an intermediate step in a process that begins with the organizing drive and ends with a contract.

The most common steps in that process are shown schematically in Figure 1. ${ }^{1}$ A group of workers decide to try to form a union, either on their own or through the instigation of a sympathetic union. The organizers then start a "card drive." To petition the NLRB to hold an election, the petitioners must submit proof, most often in the form of signed

${ }^{1}$ This diagram has been adapted from the summary in DiNardo and Lee (2004). 
cards, that at least $30 \%$ of the employees in the proposed bargaining unit desire such an election. In practice, most organizers gather cards from two-thirds or more of the employees, since the share of cards is a signal of likely election success (Fiorito 2003:200). If the organizers gather enough signatures to submit a petition, then the NLRB rules on, inter alia, the appropriateness of the suggested bargaining unit. Assuming that the NLRB goes forward with the unit as suggested or modified, the parties then come to an agreement on the type and date of election. Within seven weeks on average after the petition has been filed, the NLRB holds an election at the workplace. A simple majority of the votes cast is necessary for a win. If the union wins and there are no objections to the conduct of the election, then the NLRB certifies the union as the representative for the bargaining unit. The employer is then obligated to bargain "in good faith" with the union for at least one year. After an average of ten months, the two sides agree on the terms of a first contract. Such first contracts cover three years, on average.

Lengthy as it is, the above is an idealized process. It can break down at several points, the most important four of which are noted as choices in Figure 1. The organizers can fail to gain enough signed cards to file an election petition. They can choose to withdraw their petition rather than to hold the election. They can lose the election. Even if they win the election, they may not reach a first contract with the employer.

\section{Sequential Model}

Breaking the organizing drive down into stages shows how it resembles a screening process, where only some of the cases in each stage advance to the next. As shown in Figure 1, of 22,382 organizing drives that filed an election petition, only a projected 3,180 - one-seventh—reached a first contract within a year of certification. Furthermore, Table 1 shows that cases that experienced a pre-election ULP charge were screened out at higher rates than other cases at each stage.

There are four mutually exclusive outcomes for organizing drives that have filed
Figure 1. Major Steps to First Contract When Organizing through an NLRB-Certified Election, with Sample Numbers.

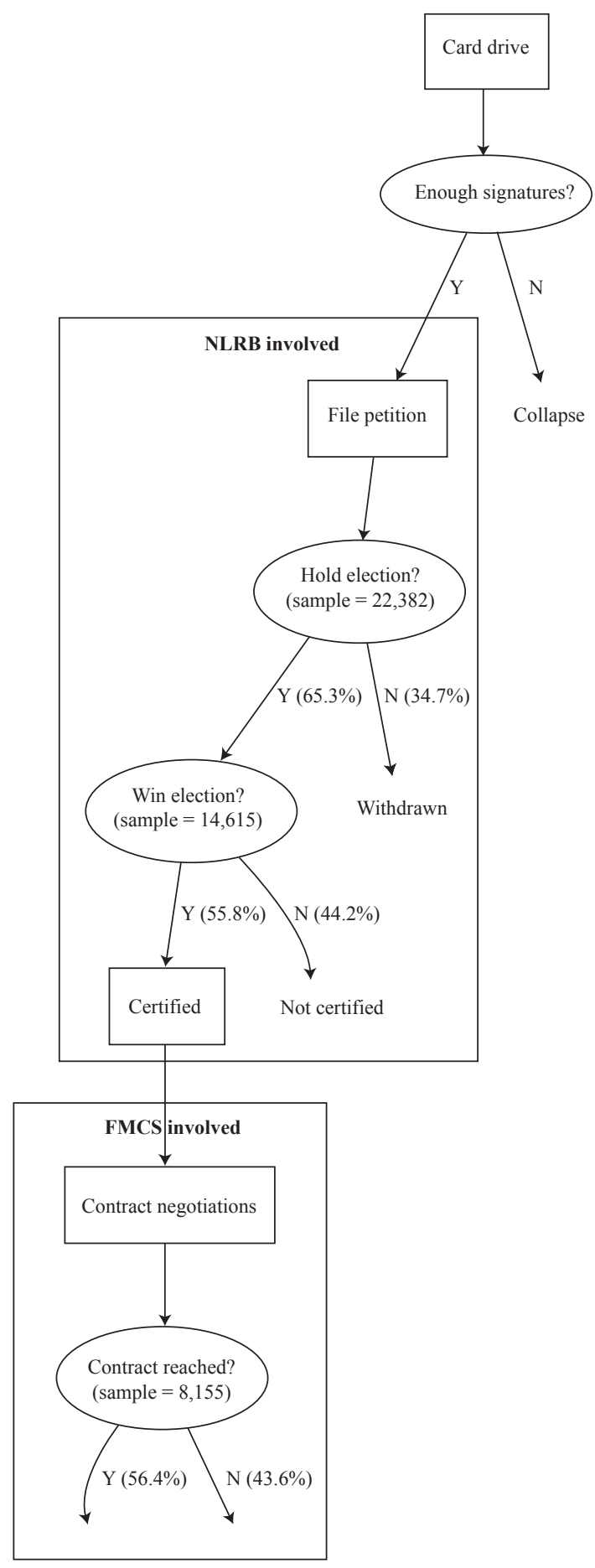


Table 1. Survival Rates for Stages of the Organizing Process

\begin{tabular}{lccccc}
\hline Stage & Cases & Rate & Non-ULP & ULP & Non-ULP:ULP \\
\hline Election Petition Filed & 22,382 & N.A. & 18,429 & 3,953 & $4.7: 1$ \\
Election Held & 14,615 & .65 & 12,410 & 2,205 & $5.6: 1$ \\
Election Won & 8,155 & .56 & 7,053 & 1,102 & $6.4: 1$ \\
Contract Agreed $^{a}$ & 3,180 & .38 & 2,777 & 403 & $6.9: 1$ \\
\hline
\end{tabular}

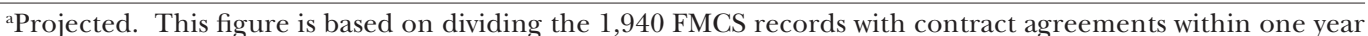
by 0.61 , the share of the total victorious election cases with matched FMCS records: $N_{\text {proj }}=1,940 / .61=3,801$. The figure is for contracts concluded within one year, the span of the contract bar. The rate for contracts agreed to within two years is .56 .

petitions with the NLRB:

A. The union can withdraw its election petition before an election is held $\left(Y_{1}=0\right)$.

B. The union can go through with the election and lose $\left(Y_{1}=1, Y_{2}=0\right)$.

C. The union can win the election but fail to secure a first contract with the employer $\left(Y_{1}=1\right.$, $Y_{2}=1, Y_{3}=0$ ).

D. The union can secure a first contract $\left(Y_{1}=1\right.$, $\left.Y_{2}=1, Y_{3}=1\right)$.

The organizing drive can be modeled as a chain of binary variables $Y_{1}, Y_{2}$, and $Y_{3}$ that are realized sequentially. Stages 1, 2, and 3 represent the three screens-holding an election, winning that election, and reaching a contract—through which a drive must pass. Later stages are subject to selection in earlier stages. Prior research on similar multi-stage processes (Lillard and Willis 1994; Upchurch etal.2002) has modeled the outcomes of each stage as realizations of a latent variable. If $y_{j}^{*}$ is the latent variable for stage $j$, then

$$
y_{j}^{*}=x_{i j}^{\prime} \beta_{j}+u_{i j}, \text { and }\left\{\begin{array}{l}
y_{i j}=0 \text { if } y_{i j}^{*} \leq 0 \\
y_{i j}=0 \text { if } y_{i j}^{*}>0,
\end{array}\right.
$$

where $i$ indexes organizing drives, $x_{i, j=1,2,3}$ are vectors of covariates, and $\beta_{j=1,2,3}$ are vectors of parameters to be estimated. Some covariates, such as the unemployment rate, may be included in all three stages, while others, such as what type of election agreement is signed, may only appear in certain stages. The parameters on particular covariates can but need not vary across stages.

The probabilities of each of the four outcomes $A$ through $D$ can then be written as

$$
P(A)=P\left(u_{i 1} \leq-x_{i 1}^{\prime} \beta_{1}\right)=\Phi\left(-x_{i 1}^{\prime} \beta_{1}\right)
$$

$$
\begin{aligned}
P(B) & =P\left(u_{i 1}>-x_{i 1}^{\prime} \beta_{1}, u_{i 2} \leq-x_{i 2}^{\prime} \beta_{2}\right) \\
& =\Phi_{2}\left(-x_{i 1}^{\prime} \beta_{1},-x_{i 2}^{\prime} \beta_{2} \mid \Omega_{1}\right)
\end{aligned}
$$

$$
\begin{gathered}
P(C)=P\left(u_{i 1}>-x_{i 1}^{\prime} \beta_{1}, u_{i 2}>-x_{i 2}^{\prime} \beta_{2}\right. \\
\left.u_{i 3} \leq-x_{i 3}^{\prime} \beta_{3}\right)=\Phi_{3}\left(-x_{i 1}^{\prime} \beta_{1}, x_{i 2}^{\prime} \beta_{2},-x_{i 3}^{\prime} \beta_{3} \mid \Omega_{2}\right)
\end{gathered}
$$

$$
\begin{gathered}
P(D)=P\left(u_{i 1}>-x_{i 1}^{\prime} \beta_{1}, u_{i 2}>-x_{i 2}^{\prime} \beta_{2},\right. \\
\left.u_{i 3}>-x_{i 3}^{\prime} \beta_{3}\right)=\Phi_{3}\left(-x_{i 1}^{\prime} \beta_{1}, x_{i 2}^{\prime} \beta_{2}, x_{i 3}^{\prime} \beta_{3} \mid \Omega_{3}\right),
\end{gathered}
$$

where $\Phi, \Phi_{2}$, and $\Phi_{3}$ are cumulative univariate, bivariate, and trivariate normal densities, respectively. The $\Omega$ matrices require a brief explanation.

If the three stages were mutually independent, then each stage could be estimated with a separate probit, and the probability of passing through the entire process would equal the product of the probabilities of passing through each of the stages (Lahiri et al. 1995). ${ }^{2}$ Yet there are strong reasons to expect the outcomes across stages of the organizing drive to be correlated. If, for example, the union's decision to withdraw depends on the likelihood that the union will win the election, then the error terms of $P(B)$ and $P(C)$ will be correlated. ${ }^{3}$ This is similar to assuming that $u_{i j}=\delta_{i}+\varepsilon_{i j}$ with $\delta_{i} \sim N\left(0, \sigma^{2}\right)$ and $\varepsilon_{i j} \sim N(0,1)$, and interpreting $\delta_{i}$ as unobserved favorable (unfavorable) conditions in a workplace that make an organizing drive more (less) likely to succeed. Specifically, this would imply that $\left(u_{i 1}, u_{i 2}, u_{i 3}\right)$ follows a multivariate normal distribution with mean zero and variance $\Omega$ :

${ }^{2}$ That is, $P(D)=\Phi\left(x_{i 1}^{\prime} \beta_{1}\right) \Phi\left(x_{i 2}^{\prime} \beta_{2}\right) \Phi\left(x_{i 3}^{\prime} \beta_{3}\right)$.

${ }^{3}$ I am grateful to an anonymous reviewer for detailing the possible sources of correlation. 
$\left.\left(u_{i 1}, u_{i 2}, u_{i 3}\right)^{\prime} \sim N \| \begin{array}{l}0 \\ 0 \\ 0\end{array}\right),\left(\begin{array}{lll}1 & \rho_{21} & \rho_{31} \\ \rho_{21} & 1 & \rho_{32} \\ \rho_{31} & \rho_{32} & 1\end{array} \|\right.$

The variances of the error terms are assumed to equal 1 so that the $\rho_{i j}$ s can be interpreted as correlations across stages (Gao et al. 2001). ${ }^{4}$ The matrices $\Omega_{1}, \Omega_{2}, \Omega_{3}$ are then defined as follows:

$$
\begin{gathered}
\left.\Omega_{1}=\mid \begin{array}{ll}
1 & \rho_{21} \\
\rho_{21} & 1
\end{array}\right) \\
\Omega_{2}=\left|\begin{array}{lll}
1 & -\rho_{21} & \rho_{31} \\
-\rho_{21} & 1 & -\rho_{32} \\
\rho_{31} & -\rho_{32} & 1
\end{array}\right| \\
\Omega_{3}=\left|\begin{array}{lll}
1 & -\rho_{21} & -\rho_{31} \\
-\rho_{21} & 1 & \rho_{32} \\
-\rho_{31} & \rho_{32} & 1
\end{array}\right|
\end{gathered}
$$

I therefore model the organizing drive as a three-stage correlated sequential probit. The correlation among the stages' error terms means that a joint marginal likelihood function must be maximized. (For details concerning the procedure, see the technical appendix to Upchurch et al. [2002].) ${ }^{5}$

The advantage of such a model can be seen, for example, when considering the effect of a ULP charge against the employer (denoted $U)$ at some point between petition and election. ${ }^{6}$ Even if a single-stage model, $\widetilde{P}(C)=$ $\Phi\left(x_{i 2}^{\prime} \gamma_{2}\right)$, gives an unbiased estimate of $\hat{\gamma}_{2}^{U}$, the total impact of the ULP charge consists not just of its effect on electoral success but also of the changed likelihoods of holding an election $\left(\hat{\beta}_{1}^{U}\right)$ and reaching a first contract $\left(\hat{\beta}_{3}^{U}\right)$. Worse, the single-stage model is likely to give biased estimates of $\hat{\gamma}_{2}^{U}$ for the reasons discussed here. A single-stage election model is thus likely to misstate the effect of the ULP charge on the final outcome of interest, a

${ }^{4}$ This is also a necessary restriction for the model to be identified (Waelbroeck 2005).

${ }^{5}$ The correlated model is estimated using aML (Lillard and Panis 2003).

${ }^{6}$ For a detailed description of ULPs, see McGuiness and Norris (1986:10-17). change in employment relations symbolized by a first contract, by $\hat{\beta}_{1}^{U} \hat{\beta}_{3}^{U} \rho_{12} \rho_{23} \rho_{13}$.

Modeling the organizing process as a single stage introduces two further problems. First, it forces the covariates' parameters to be the same at each stage. This is unlikely to hold in reality. Three choice processes are at work in these drives. Some criteria will be relevant to the decision-makers at one stage and not to those at another, and so the coefficients should change. Second, a single-stage model either excludes observations that never reached contract negotiations or uses the covariates on cases that were screened out earlier to determine coefficients for the later outcome. A multi-stage model addresses both of these problems by allowing coefficients to vary between stages and by only considering the population of interest at each stage.

\section{The Study Data}

\section{Data Sources}

Figure 1 shows that two federal agencies, the NLRB and the Federal Mediation and Conciliation Service (FMCS), become involved at different stages of the organizing drive. The NLRB formally oversees all election drives from the filing of the election petition to the certification of the election results. The FMCS can be involved in firstcontract negotiations; pursuant to its interest in labor peace, in recent years it has tried to gather data on all first-contract negotiations. Freedom of Information Act requests were filed with both agencies, to request all of the NLRB's representation and ULP cases that were closed between October 1, 1999, and June 1, 2005, and all of the FMCS's first-contract cases over the same period. October 1 , 1999 was chosen as the starting date because in 1999 the NLRB switched to a new database system that complicated comparisons to previous records, and because the FMCS's effort to obtain information on all first-contract negotiations (discussed below) aimed to enter data back to that date. Because union certification directs the employer and employees' representative to bargain in good faith for one year before decertification or other actions can be proposed, this study uses 
NLRB cases closed through June 1, 2004, so that the FMCS records will contain the year's negotiations. After duplicated records and other data-entry errors were removed, the NLRB records yielded data for 22,382 cases. $^{7}$ The representation cases' recording of ULP charges is incomplete. I therefore matched the representation cases with the case data for all the ULP charges closed during the same period. I found a ULP charge associated with just over one-fifth of the representation cases.

To anyone familiar with union organizing in the United States, a one-in-five chance of a ULP charge might sound low. The figure is an artifact of when these drives become observable in the NLRB's records. The NLRB opens a representation case when a union, individual, or employer submits a petition to hold an NLRB-certified representation election. To file such a petition, as described above, the filer must first have signed proof of at least $30 \%$ support among the employees in the proposed bargaining unit. The NLRB's records thus cover only those organizing drives that passed through the signature screen. Any ULP charges during a card drive will show up as ULP cases, but if the drive ends without a petition filing, there will be no representation case to match it to. The share of drives that end in this early stage is difficult to estimate, but several researchers have cited anecdotal evidence that up to half of all organizing drives do end early-when, for example, the prompt firing of a vocal union supporter stands a good chance of nipping the drive in the bud (Fiorito and Bozeman 1997; Cohen and Hurd 1998). ${ }^{8}$ The one-in-five figure should be interpreted thus: in one-fifth of the organizing drives in which

\footnotetext{
${ }^{7}$ Virtually all the 14,002 eliminated records were duplications. When the NLRB added information to a case, the result was often the appearance of a new record in the database, rather than overwriting of the less-complete record. I removed fewer than 100 cases with other errors. The final number of cases, 22,382, is less than half the number found for a similar period 25 years earlier (Heneman and Sandver 1983:537).

${ }^{8}$ The NLRB staff members who helped me assemble the data also said that they handled about as many complaints related to card drives as to later stages in the process.
}

an election petition was filed, one of the parties subsequently filed a ULP charge.

I then matched these NLRB records with the FMCS's records on first-contract negotiations. The records that are needed to track the full organizing process have not been combined before, despite efforts up to and including the Dunlop Commission's work during the Clinton administration (Dunlop Commission 1994). Shortly after the Dunlop Commission issued its report in 1994, the NLRB and the FMCS resolved to cooperate to improve the services they provide to firstcontract cases. As part of that cooperation, the NLRB agreed to give the FMCS copies of certifications issued by the Board and regional offices, and the FMCS agreed to assign those cases to mediators upon receipt. For several years the agencies traded paper records, which delayed action. In 2003, the two agencies established a monthly computer transfer of all newly certified units from the NLRB's records to the FMCS. The first transfer included the NLRB's recorded certifications back to October 1, 1999, when they switched to their new database. The FMCS began incorporating those records into its own case-tracking database, disseminating the relevant records to its field offices and assigning mediators. Meanwhile, Washington staff began back-filling the information for earlier certifications by cross-checking their own records and contacting bargaining units.

The FMCS had mixed success involving mediators in first-contract negotiations. In most cases, the mediator merely called the parties to determine whether a contract had been reached. For this study's purposes, this limited involvement is actually useful. In the past, FMCS contact with first-contract negotiations occurred only when the parties asked the agency for help; this obviously produced a self-selected sample of cases. These data, in contrast, reflect the FMCS's effort to make contact in all cases.

The FMCS's efforts to gather case information for all first-contract negotiations are still incomplete; of all the representation cases that ended with certification of the union, I found a corresponding case in the FMCS's records for only $61 \%$. To explore whether 
the remaining $39 \%$ of cases were unmatched at random, I performed a selection test on the observables in both datasets. I found no statistically significant differences. Although this is the strongest test for sample-selection bias I can perform using the available data, it is admittedly weak, because there is relatively little information in the NLRB records.

Data for additional controls come from several sources. The unemployment rate for each county-month in the sample comes from the Local Area Unemployment Statistics gathered by the Bureau of Labor Statistics. The data on the union density of each Metropolitan Statistical Area (MSA) come from Hirsch and Macpherson's analyses of the Current Population Survey (Hirsch and Macpherson 2004). Industry identifiers for all years were coded to be consistent with the 1997 NAICS (North American Industry Classification System) codes published by the BLS. Party control of the NLRB was determined by the NLRB's list of board members since 1935. The presence of right-to-work laws was confirmed by checking the records of the National Right to Work Foundation.

The resulting dataset, which contains 14,754 cases with data present for all variables, paints a fuller picture of union gestation and birth than has heretofore been available on a national scale. The records track proposed bargaining units from the earliest point for which we have data through election to first-contract negotiation. In particular, most studies that have looked at the early effects of unionization have not had data on whether a first contract was reached, but only on whether a first contract expired (DiNardo and Lee 2004:256-57). Relying on contract expiration would be useless here, since all such cases must have reached a first contract. Gathering data on the first-contract negotiations avoids this censoring problem.

\section{Variables}

Since the model covariates change in each stage, they are grouped here by the stage in which they are introduced. Similarly, the reported results in Table 3 include summary statistics for each covariate among the population of interest in that stage.
In stage 1 the dependent variable is whether the union organizers held an election or withdrew the election petition. The main independent variable of interest is whether the organizers filed a ULP charge before the election. There are several types of ULP charges. An 8(a) (1) charge corresponds to attempts to "interfere with, restrain, or coerce employees in the exercise of their rights to engage in concerted or union activities or refrain from them," and an 8(a) (3) charge corresponds to attempts "to discriminate against employees for engaging in concerted or union activities or refraining from them." 8(a) (3) charges are often associated with firings for union activity. Together, these two charges account for $88.4 \%$ of the ULP charges filed. The remainder are in the "other charge filed" category.

ULP charges are an awkward measure of illegal activity by employers, because union organizers can file them for strategic reasons even when no illegal activity has taken place. Although there is no fool-proof way to tell whether illegal activity actually took place, one indication is whether the NLRB found the charge meritorious. Thus the model also includes six indicator variables: all 8(a) (1) charges; all 8(a) (3) charges; all "other" charges; and, within each of those three categories, the subset of charges that were found meritorious. Table 2 shows the resulting breakdown of cases. The comparison group is cases in which no ULP charges were filed.

Stage 1 also includes delay, measured as the log number of days between the filing of the petition and either the election or withdrawal. Because unions have some control over the election date through their choice of when to file the petition, most research has assumed that they strike while the iron is hot (Freeman and Kleiner 1990). Delays therefore are intervals during which employers can campaign against the union (Riddell 2004) and doubt can form in the employees' minds (Montgomery 1989). Yet the negative relationship between delays and organizing success has rarely been attributed to delay itself but rather to unfavorable events, such as employers' filing clarification charges about the scope of the bargaining unit, that both 
Table2. Breakdown of Cases by Experience of Pre-Election and Post-Certification ULP Charges.

\begin{tabular}{|c|c|c|c|c|c|c|}
\hline \multicolumn{6}{|c|}{ ULP Filed, 2,627 } & \multirow{2}{*}{$\begin{array}{c}\text { No ULP Filed, } \\
12,127\end{array}$} \\
\hline $8(a)(1)$ & $8(a)(1)$, Merit & $8(a)(3)$ & $8(a)(3)$, Merit & Other & Other, Merit & \\
\hline 644 & 749 & 387 & 165 & 519 & 163 & \\
\hline \multicolumn{7}{|c|}{ Won Certification Election } \\
\hline 124 & 145 & 85 & 26 & 145 & 40 & 5,356 \\
\hline \multicolumn{7}{|c|}{ Post-Certification ULP Charge } \\
\hline 40 & 20 & 10 & 6 & 20 & 5 & 591 \\
\hline
\end{tabular}

Notes: Total number of cases, 14,754. The sample of cases broken down here includes all cases used in subsequent analyses.

produce delay and make victory less likely (such charges take time to resolve, may be spurious, and when not may either exclude pro-union employees from or group antiunion employees in the electorate). Here, therefore, delay is included as a control, to try to capture the impact of ULP charges distinct from other conditions that would produce delays. ${ }^{9}$ Since all organizing drives take a certain amount of time between petitioning and election, the effect of delay is expected to be positive but decreasing.

Larger bargaining-unit size has long been hypothesized to lower the likelihood of organizing success (see, for example, Flanagan 1989). For this stage, I measure size using the log number of employees on the election petition, because the NLRB's determination of the specific boundary of the bargaining unit happens later, and indeed may not happen at all for a drive that ends in withdrawal of the petition. The unemployment rate is assumed to be inversely related to organizing success, since workers have less fear of termination or other employer retaliation in tight labor markets (Hoxie 1923). The effect of union density in a given area (here, the MSA) has been debated: Lipset et al.

${ }^{9}$ The average case that went to election did so in 41 days, and $95 \%$ of elections were held within 75 days of filing. The tail, however, is quite long; the maximum delay before election recorded in the data is 1,705 days. The relationship between delay and withdrawal is noticeable when all cases, not just those that went to election, are considered. The average time to election or withdrawal was 50 days, and cases in the 95 th percentile were open for 234 days.
(1956) argued that the relationship would turn negative as unions moved from the easy to more difficult drives, but most researchers have assumed that union density proxies for a pro-union climate and thus will have a positive effect (Hurd and McElwain 1988). The presence of right-to-work laws is often used as a proxy for an anti-union climate (Montgomery 1989), though the mechanism by which the laws would lower success rates has rarely been specified (Wessels 1981). The model includes two time-period indicators, for whether the organizing drive took place under the Bush administration with (a) a Democrat-controlled Board or (b) a Republican-controlled Board. ${ }^{10}$ The comparison group is cases from the Clinton administration. Finally, the model controls for union and three-digit industry. The comparison group is SEIU organizing drives in the nursing industry. ${ }^{11}$

Most of these variables' effects have been proposed in terms of predicting election outcomes. Farber (2001), for example, suggested that large units would be less likely than smaller ones to vote for a union because votes follow a binomial distribution, and

${ }^{10}$ Democrats controlled the Board during Bush's first year in office; retirements and new appointments in January 2002 gave control to the Republicans.

${ }^{11}$ The SEIU and nursing are the second most common union and industry, respectively, in the data. The Teamsters and specialty construction are the most common. To give the union and industry coefficients some more substantive meaning, I chose a group that was relatively generalizable on both dimensions. The SEIU has been active in many industries, and many unions have tried to organize nursing employees. 
thus anything that lowered (or raised) the underlying average propensity to vote union would have a larger effect on outcomes in larger units. If the negative effect of unit size really is just an artifact of the underlying vote distribution, then we would not necessarily see any such effect of unit size before elections. Right-to-work laws are normally posited to reduce union-organizing success by reducing employees' incentive to join a union whose benefits they will in either case receive. If employees are aware of such laws and their effects, then they should be unenthusiastic about organizing drives in general. In this case, then, the effects would be more likely to show up before elections. By examining this earlier stage, we can look for different effects of these and other controls.

In stage 2 the dependent variable is a binary variable recording union election victory. This is the stage that most previous studies have modeled (see, for example, Cooke 1983). The main independent variables remain the existence of various pre-election ULP charges. Bargaining-unit size is here measured as the log number of eligible voters. The model controls for whether an election agreement was signed and whether that agreement was a "consent" or "stipulated" agreement (Cooke 1983; Peterson et al. 1992). ${ }^{12}$ Stage 2 also includes delay and the other controls from stage 1. Because all members of the population considered in stage 2 go to election, the initial positive effect of delay from stage 1 should not appear; instead, the negative effect should dominate.

In stage 3 the dependent variable is reaching a first contract with the employer. The FMCS followed newly certified units for up to two years and noted both whether and when a contract was negotiated in that time span. For the purposes of the law, however, the important question is whether the two parties negotiated a contract within one year of certification-the "contract bar" period during which neither the employer nor other unions may challenge the certified union's

${ }^{12}$ Consent elections were extremely rare in this period; only $1.13 \%$ of the cases in which election agreements were signed also saw the signing of consent agreements. status as the employees' representative. Thus the contract variable is coded one when a contract is reached within one year of certification and zero otherwise. ${ }^{13}$

ULP charges are more complicated in this stage. This is because the parties can file new ULP charges, typically 8(a) (5) charges over the employer's refusal to bargain, during contract negotiations. The model therefore includes an indicator of whether a ULP charge was filed after certification. ${ }^{14}$ It also includes interaction terms between the postcertification ULP charge and any earlier ones, to determine whether the combined effect is stronger than the two effects in isolation.

Stage 3 also includes certification delay, measured as the log number of days between the election and the NLRB's final certification of the union. Here again, delay is a proxy for other factors that are likely to influence the tenor of the negotiations. ${ }^{15}$ The unit size can now be measured directly. Other controls are implemented as in stages 1 and 2 . Table 3 reports the summary statistics for the covariates in each stage.

\section{Data Analysis}

Table 4 reports the regression results. It shows two models. In the first, the three stages have been estimated independently of one another. In the second, the error terms across the stages have been allowed to be correlated, to help account for endogeneity between the stages.

\footnotetext{
${ }^{13}$ Two-thirds of the recorded contracts in the data were reached within one year; $95 \%$ were reached within two years. Coding all contracts reached in the data, regardless of time between certification and contract, produces similar results. Tables showing this more generous specification of the dependent variable and other analyses are available from the author upon request.

${ }^{14}$ The bulk of evidence for these charges came from the FMCS's records, where the relevant section of the NLRA is not cited. Therefore I do not distinguish different types of post-certification charges.

${ }^{15}$ At the certification stage, as at the other stages, delays tended to be either nonexistent or quite long. Half of all cases were certified within one and a half weeks of the election, and three quarters within three weeks; but those in the 95 th percentile were not certified for more than five months, and the longest wait was eighteen months after the election.
} 
Table 3. Summary Statistics for Regressions.

\begin{tabular}{|c|c|c|c|}
\hline \multirow[b]{2}{*}{ Variable } & \multicolumn{3}{|c|}{ Stage } \\
\hline & 1 & 2 & 3 \\
\hline Election Held & .672 & & \\
\hline Election Won & & .559 & \\
\hline Contract Reached & & & .383 \\
\hline 8(a) (1) Charge Filed & .044 & .041 & .033 \\
\hline 8 (a) (1) Charge with Merit & .051 & .041 & .039 \\
\hline 8(a) (3) Charge Filed & .026 & .025 & .024 \\
\hline 8(a) (3) Charge with Merit & .011 & .008 & .010 \\
\hline Other Charge Filed & .035 & .028 & .028 \\
\hline Other Charge with Merit & .011 & .009 & .011 \\
\hline Post-Certification ULP Charge & & & .138 \\
\hline Log Employees on Petition & 3.210 & & \\
\hline Log Eligible Voters & & 3.297 & \\
\hline Log Bargaining-Unit Size & & & 3.133 \\
\hline Consent Agreement & & .008 & \\
\hline Stipulated Agreement & & .880 & \\
\hline Log Election Delay & 3.522 & 3.738 & \\
\hline$(\text { Log Election Delay })^{2}$ & 12.983 & 14.113 & \\
\hline Certification Delay & & & 2.734 \\
\hline (Certification Delay) $^{2}$ & & & 8.144 \\
\hline Unemployment Rate & 5.330 & 5.283 & 5.154 \\
\hline MSA Density & 10.965 & 10.988 & 11.156 \\
\hline Right-to-Work State & .170 & .167 & .167 \\
\hline Bush Admin, Dem. Board & .173 & .171 & .208 \\
\hline Bush Admin, Rep. Board & .554 & .544 & .450 \\
\hline Observations $^{\mathrm{a}}$ & 14,754 & 9,919 & 3,613 \\
\hline
\end{tabular}

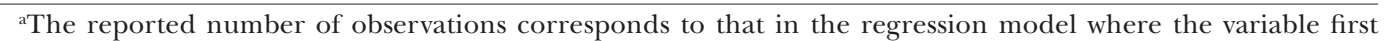
appears.

The strong and statistically significant correlation between the first two stages' errors $\left(\rho_{\varepsilon \eta}\right.$ in Table 4) suggests that endogeneity is present in the process-most likely, that unions' decision to withdraw their petitions is based in part on their expectations of election success. And while the signs and significance levels are largely unchanged across the two models, the point estimates do differ between them, suggesting that the coefficients in model 1 may suffer from endogeneity bias. I therefore focus on the coefficients reported in model 2 and compare them to the model 1 coefficients when appropriate.

All ULP charges, both those that were found meritorious by the NLRB and those that were not, were significantly and negatively correlated with holding an election, and meritorious charges were generally associated with stronger negative effects, as expected. Some idea of the magnitude of these effects can be gained by calculating the change in the probability of holding an election associ- ated with the presence of a ULP charge. The likelihood that an SEIU organizing drive in nursing (the comparison category) that faced the mean delay and unemployment held an election is .624. Following Petersen (1985), we can calculate the change in probability of holding an election given a meritorious $8(\mathrm{a})$ (3) charge (denoted $F)$ as

$$
\begin{aligned}
\Delta P & =\frac{P(B \mid F=1)-P(B \mid F=0)}{P(B \mid F=0)} \\
& =\frac{\phi\left(x^{\prime} \beta_{1}-\beta_{1}^{F}\right)-\phi\left(x^{\prime} \beta_{1}\right)}{\phi\left(x^{\prime} \beta_{1}\right),}
\end{aligned}
$$

where $\beta_{1}{ }^{F}$ is the coefficient on a meritorious 8 (a) (3) charge given in model 2 of Table 4 and $\phi$ is a standard normal distribution. ${ }^{16}$ In this case, the change in probability is equal

${ }^{16}$ The same procedure is used to interpret coefficients elsewhere in the paper. 
Table 4. Independent and Correlated Sequential Probit Results

for Holding and Winning Elections and Reaching First Contracts.

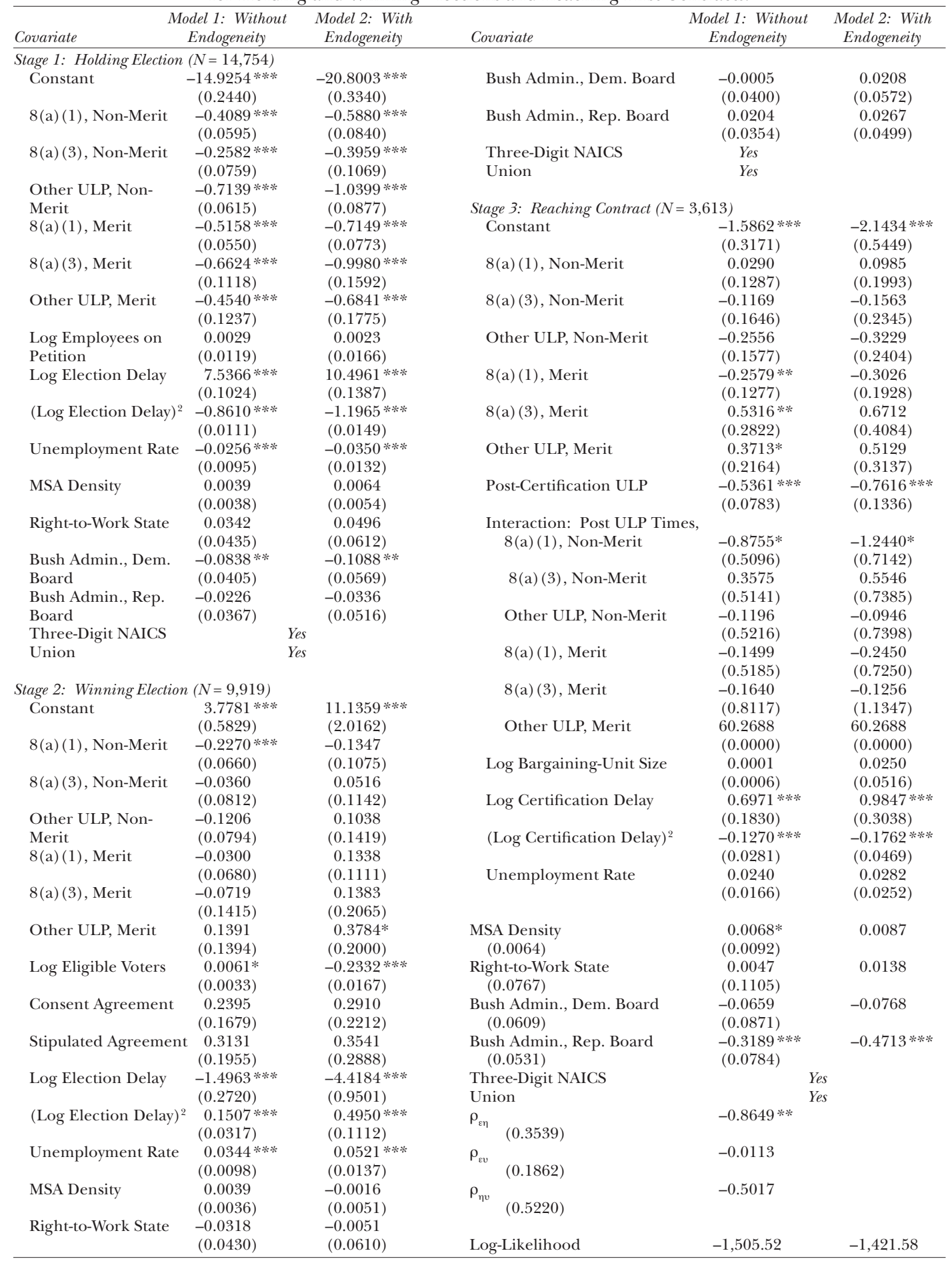

Notes: Asymptotic standard errors are in parentheses. All models include controls for 3-digit industry and union. $P_{b}=.65, P_{c}=$ $.56, P_{d}=.38$. A longer table showing all industry and union coefficients is available from the author upon request.

$*$ Statistically significant at the .10 level; **at the .05 level; ***at the .01 level. 
Table 5. Changes in the Probability of Holding an Election Based on ULP Charges.

\begin{tabular}{lccc}
\hline Charge Type & Merit & $\Delta P(\%)$ & $N$ \\
\hline $8(\mathrm{a})(1)$ & $\mathrm{N}$ & -16.5 & 644 \\
$8(\mathrm{a})(3)$ & $\mathrm{N}$ & -2.6 & 387 \\
Other & $\mathrm{N}$ & -44.1 & 519 \\
$8(\mathrm{a})(1)$ & $\mathrm{Y}$ & -25.6 & 749 \\
$8(\mathrm{a})(3)$ & $\mathrm{Y}$ & -39.4 & 165 \\
Other & $\mathrm{Y}$ & -21.8 & 163 \\
Mean & & -24.6 & 2,627 \\
\hline
\end{tabular}

Notes: Results are based on a correlated sequential probit. A model without endogeneity produces a mean effect of $-34.1 \%$.

to -.394 ; thus, elections are nearly $40 \%$ less likely in cases with meritorious 8(a)(3) charges than in those without.

Table 5 shows results for similar calculations for all types of ULP charges as well as the mean effect across types. The mean effect is a $25 \%$ higher chance of withdrawal. The smaller magnitude of this effect than of that estimated using the independent sequential models $(34 \%)$ lends further credence to the idea that some labor organizations that both withdraw their bid for an election and file ULP charges do so with the expectation of poor performance in the election. The independent model attributes that negative effect to the charge and thus overstates its impact. Still, the negative effect is statistically significant and substantial even after correcting for endogeneity.

Most of the controls are statistically significant in the expected directions. The effect of delay is curvilinear, and the positive effect peaks at day 80 , which is well within the sample but after most drives that ultimately go to election have done so. Raising the unemployment rate by a percentage point lowers the probability of holding an election by almost $15 \%$-non-trivial, but smaller than the effect of most ULP charges. Unit size, MSA density, and right-to-work status are not statistically significant at this stage. The first two years of the Bush administration, with a Democrat-controlled Board, were less likely to see drives go to election than were earlier or later periods.

In stage 2 the effects of ULP charges were not statistically significant. ${ }^{17}$ This is consistent with earlier findings (Ahlburg 1984; Cooke and Gautschi 1982) and with the assumption that organizers self-select into election. The negative effect of unit size appears here as it did in earlier studies: a one-standard-deviation increase in the log number of voters (from a mean of 27 to 97) reduces the likelihood of electoral success by $38 \%$. Delay here is negative and decreasing, with a minimum at 88 days. Unemployment, somewhat surprisingly, is positively correlated with election victory, though this too jibes with organizers' deciding to press on with elections rather than withdraw despite the unemployment rate. There are no statistically significant period effects. ${ }^{18}$

In stage 3 , delays in certification did have positive and then negative effects, peaking at 12 days. Since half of all units were certified within 10 days of a victorious election, it makes sense simply to think of any delays in certification as being negatively correlated with reaching a contract. Also in this stage, as in stage 2, the direct effect of ULP charges was not statistically significant. ${ }^{19}$ ULP charges filed after certification, however, had a large negative effect: organizing drives with such charges were $77.7 \%$ less likely to reach a first contract than were those without them. The negative impact was even larger-89\%-in cases where 8(a) (1) charges had been filed before the election. One further and worrying effect in the model is the declining likelihood of reaching a first contract over time.

\footnotetext{
${ }^{17}$ In cases where "other" charges were found meritorious, organizers were more likely to win elections. There is no obvious explanation for this effect, given the composite nature of the category.

${ }^{18}$ Electorally, the SEIU is one of the most successful unions. Using it as the comparison group is thus a conservative test for ULP effects. Including interaction terms for all the unions requires too many variables for most programs to estimate. Estimating a model with no union controls (available upon request) produces weakly significant negative effects for 8 (a) (1) charges with and without merit, which suggests that there is further fallout from such charges during elections for some unions.

${ }^{19}$ In both stages the independent model shows negative effects for 8(a) (1) charges, but these effects disappear when correlation between the events is accounted for.
} 
Table 6. Likelihood of Success in Different Stages, by Presence and Type of ULP Charges, Including Average and Cumulative Effects of a ULP Charge.

\begin{tabular}{|c|c|c|c|c|c|c|}
\hline \multirow{4}{*}{$\begin{array}{l}\text { Was a ULP Charge Filed } \\
\text { before Election? }\end{array}$} & \multicolumn{4}{|c|}{ Likelihood of Success at a Given Stage } & \multirow{4}{*}{$\begin{array}{l}\text { Cumulative } \\
\text { Likelihood }\end{array}$} & \multirow{4}{*}{$\begin{array}{c}\text { Change in } \\
\text { Cumulative } \\
\text { Likelihood ( \% }\end{array}$} \\
\hline & \multicolumn{4}{|c|}{ Reaching Contract: } & & \\
\hline & Holding & Winning & No Later & Later & & \\
\hline & Election & Election & $U L P$ & $U L P$ & & \\
\hline No ULP Filed & .624 & .558 & .410 & .093 & .129 & \\
\hline 8(a) (1) Filed, n.m. & .521 & .558 & .410 & .045 & .085 & -34 \\
\hline 8(a) (3) Filed, n.m. & .608 & .558 & .410 & .093 & .126 & -3 \\
\hline Other ULP Filed, n.m. & .349 & .558 & .410 & .093 & .071 & -45 \\
\hline 8 (a) (1) Filed, m. & .464 & .558 & .410 & .093 & .095 & -26 \\
\hline $8(\mathrm{a})$ (3) Filed, m. & .378 & .558 & .410 & .093 & .071 & -45 \\
\hline Other ULP Filed, $\mathrm{m}$. & .488 & .625 & .410 & .093 & .104 & -52 \\
\hline Average ULP & .491 & .562 & .410 & .081 & .091 & -30 \\
\hline $\begin{array}{l}\text { Average Change in Likelihood } \\
\text { of Success }(\%)\end{array}$ & -25 & 1 & 0 & -13 & -30 & \\
\hline
\end{tabular}

Note: All probabilities and calculations used to produce this table are available in an appendix from the author upon request.

Representation cases that were concluded under the Republican-majority Board were considerably less likely to reach agreement than comparable cases earlier in the study period.

Modeling the process this way allows us to calculate the cumulative relationship between ULP charges and the final outcome, to see where in the process ULP charges "bite." This is done by conditioning later outcomes on the estimated probability of achieving earlier outcomes. Table 6 shows the likelihood of success in each stage, varying by the presence and type of ULP charge. The top row, "No ULP Filed," shows the likelihood of success in the absence of a pre-election ULP charge. The cumulative likelihood of success can then be calculated as the product of these likelihoods, with one caveat: because later ULP charges can occur, the probability of reaching a contract is a weighted average of the probabilities of reaching a contract when there is and is not a later charge. ${ }^{20}$ Thus for a union with no pre-election ULP charges, the likelihood of eventually reaching a contract with the employer within the first year after

${ }^{20}$ Here, $P(D)=P(B) \times P(C) \times[P(D \mid U=0) \times P(U=0)$ $+P(D \mid U=1) \times P(U=1)]$, where $U$ is a post-certification ULP charge. For cases with no pre-election ULP charges, $P(U=1)=.124$. certification is $12.9 \%$. The other rows show the likelihoods of success given various ULP charges. Their cumulative likelihoods are calculated similarly.

The impact of a ULP charge at each stage and the cumulative impact vary considerably by the type of charge filed. The most common type of charge, the 8(a) (1), is associated with lower likelihoods of success in the first and third stages and a 34\% lower likelihood of passage through the entire process. In only $8.5 \%$ of such cases is the process seen through to completion. The effect is of similar size whether or not the NLRB found the charge meritorious. On the other hand, 8(a) (3) charges show striking differences depending on merit findings. While non-meritorious charges had very little effect on the final outcome, meritorious charges reduced the likelihood of success by almost half.

The bottom two rows of Table 6 show the average likelihood of success given a ULP charge, defined as the sum of the likelihood of success given each type of charge times the probability that a charge was of that type. In practice there is no such average charge, but this figure gives an estimation of the expected effect of a ULP charge of indeterminate type. Thus, for example, a ULP charge is associated with a $25 \%$ lower likelihood of holding an election, as Table 5 also showed. These average effects yield 
a cumulative likelihood of $9.1 \%$ for passing through the entire process. This is $30 \%$ lower than the $12.9 \%$ rate for organizing campaigns with no ULP charges. Furthermore, the bulk of this reduction comes from two places: the reduction in the likelihood of holding an election and the increased likelihood of exposure to ULP charges after certification. A post-election ULP charge was experienced in $12.9 \%$ of cases without pre-election ULP charges, but in $18.5 \%$ of cases with pre-election charges.

\section{Discussion}

Consistent with a view of union organizing as a multistage process, this study of organizing drives that took place between 1999 and 2004 reveals evidence that covariates had different effects on the "sifting and sorting" (Fernandez and Weinberg 1997) of cases at different points in the process. Unit size, for example, does seem to have mattered in determining election outcomes, but not in the decision to hold elections or in the likelihood that contract negotiations would succeed. ULP charges meanwhile bit where unit size did not. The data also demonstrate a worrisome recurrence of ULP charges: in cases where charges were filed yet the union went ahead with and won the election, employers did not appear to be deterred.

Some limitations of this study should be noted. ULP charges are a noisy measure of unfair labor practices- there is a risk of false positives and false negatives. Yet that measurement error should bias the coefficients on charges toward zero. There is little reason to think that measurement error has inflated the coefficients reported here. Endogeneity, on the other hand, could bias the coefficients upward (Lawler 1984; Freeman and Kleiner 1990; Koeller 1992). Comparison of the independent and correlated sequential models suggests that endogeneity is an issue, particularly in the relationship between petition withdrawals and electoral success. Union organizers almost certainly withdraw based on their expected performance in the election; if organizers in that position are also likely to file ULP charges, then the impact of those charges will be overestimated.
Similarly, employers probably commit unfair labor practices when they think doing so will have the greatest effect. Weaker drives will thus be exposed to ULPs more often, but it will be the weakness of the drive that provokes the ULP and not vice-versa. ${ }^{21}$ It is notable that calculating the average cumulative effect of ULP charges using the results from the independent model (available on request) suggests a $58 \%$ reduction in the likelihood of final success, rather than the $30 \%$ reduction yielded by the correlated model. Half the effect, in other words, is an artifact of endogeneity. Yet the $30 \%$ reduction that remains after allowing for endogeneity is still daunting, particularly when applied to an already small likelihood of success.

A central policy implication of this study is that the organizing process is broken. If workers who have expressed interest in voting whether to have a union have only a one-in-five chance of ultimately reaching a first contract, or a one-in-eleven chance when there is a ULP charge, they will quite rationally decide that the union certification process is not a worthwhile investment. While the NLRB election procedure can be modeled as a screening process, it was not designed to function this way. As designed, there were two screens: the signature requirement and the election. All of the cases observed here by definition met the signature requirement. The period before the election was not supposed to last months or years (Miller and Leaming 1962). Nor were one of every three organizing drives expected to be abandoned before an election was held, given the workers' stated preference for holding one. There certainly were not supposed to be attrition rates surpassing $40 \%$ in the interval between recognition and contract agreement. Yet even this study's upper-bound estimate of a $56 \%$ contract agreement rate within two years is lower than the rate estimated more than a decade ago (Dunlop Commission 1994).

The second policy implication is not new: policies geared to change or support work-

\footnotetext{
${ }^{21}$ In this second case, the "true" effect of the ULP charge would still be negative, for it is precisely because they think that their actions will encourage withdrawal that employers would choose to act.
} 
ers' preferences for or against unions may be misdirected. The high rates of withdrawal and deadlock during contract negotiations imply both that workers who want unions often get no chance to express that desire, and that many workers who have chosen unionization are effectively blocked from implementing it. Consequently, policy reforms or union tactics that increase the likelihood that a worker will vote for unionization should be considered as a part of this longer process. Tempering any celebration of a $10 \%$ increase in voting, for example, must be the recognition that there is only about a $62 \%$ chance of coming to election at all and a $38 \%$ chance of negotiating a contract. Relatedly, any appraisal of the intrinsic value of elections should be qualified by consideration of how many workers never get the chance to vote in one. This work poses no definitive support for either position in the current debate over card-check versus electoral recognition, but it does suggest that, ceteris paribus, substantially more workers would have been organized into unions between 1999 and 2004 if the signature screen were the final one. ${ }^{22}$ Furthermore, supportfor elections, on whatever grounds, should be backed up by support for additional reforms that will raise workers' chances of holding elections.

A tactical implication is that union organizers who choose to hold elections despite having filed ULP charges may be too optimistic about their long-term relationship with the employer. While it is true that pre-election ULP charges seem to have no effect on election outcomes, they are associated with nearly $50 \%$ higher odds of new ULP charges being filed during contract negotiations. The contract-agreement rate for this group is a dismal $25.4 \%$. Given the difficulty of reaching a contract in all other drives, it is questionable whether these acrimonious negotiations are a good use of scarce union resources. Unions may have other reasons for pushing

${ }^{22}$ This point should be tempered by the realization that, were the signature screen the final bar to union recognition, we would almost certainly see earlier employer resistance. It is wrong to say that all the organizing drives seen here to pass the signature bar would have done so under a card-check regime. such drives, and will probably continue to do so; but it is worth considering this additional cost when evaluating the relative benefits of such perseverance.

The central research implication of this study is that union organizing in America is a process both more complex and more strategic than previous work that focused on the elections might have led us to suppose. Much of the research on worker preferences for unionization trained a behavioral lens on organizing and tried to determine what forces would influence individuals' voting (Getman et al. 1976). This study suggests that such an approach overstates the influence of workers' preferences. In the stages before and after elections, unionization can be thwarted despite workers' strong preferences for it. Thus this study supports other recent work that has tried to consider individual employees' preferences as well as the opportunity structure in which those preferences can be expressed (Riddell 2004).

There is a parallel here with the evolution of status-attainment research in sociology, where the focus shifted over time from individual-specific determinants of financial or social success, like education, to organizational characteristics that influenced the opportunities that any given individual faced (Baron and Bielby 1980, 1985). Certainly we need accurate and current understanding of what precisely employees want from their relationships with their employers (Freeman and Rogers 1999), but without knowing the legal and organizational hurdles that must be cleared to build such relationships, we cannot fully explain the gap between preferences and outcomes in the workplace.

A sequential approach like the one used here complicates earlier research findings. If there are multiple mechanisms by which ULPs could influence organizing success, depending on the stage of the process considered, then there may also be multiple mechanisms by which corporate characteristics (Maranto 1988), unit size (Farber 2001), attitudes and normative pressures (Montgomery 1989), or other determinants have their effects. In particular, the fact that the group making the relevant decisions changes from stage to stage (from union organizers in stage 
1 , to workers in stage 2 , to business agents in stage 3) means that many effects will be stable across stages only insofar as they work through different agents in the same way. Yet this approach also offers a way to resolve some of those complications. Future research could test between alternative explanations that make identical predictions at one stage, if those explanations make different predictions at another stage. This study provides, for example, a crude test for evaluating some competing theories of unit size. Larger units are less likely to win elections but no less likely to hold them. Theories based on free-riding (Olson 1965) and theories based on the probability distributions of votes (Farber 2001) both predict that larger units will win elections at lower rates, but a free-rider theory should also predict that larger units would hold elections at lower rates. Thus the results presented here tentatively lend more support to a probabilistic explanation for unit size's effect than to the free-rider explanation. Similar tests could be implemented to judge between other proposed mechanisms.

There is one other, more specific, research implication. Cases in which 8(a) (3) charges were filed during this period appear to have been quite different from those studied in earlier periods (compare Kleiner 1984). Why non-meritorious 8(a) (3) charges had so little effect compared to meritorious ones is a mystery, particularly given the more comparable effects of non-meritorious and meritorious 8 (a) (1) charges.

\section{Conclusion}

Two developments encouraged the quantitative study of union-organizing drives. The first was the NLRB's and the AFL-CIO's systematic collection of administrative data on representation drives (Miller and Leaming 1962; Rose 1972). The second was the steady erosion of union success in those drives, from the mid-1970s onward. Thirty years after Getman et al. (1976) sparked the first long debate about why and how workers choose to join or avoid unions, it seems that interest in the administrative details of union representation campaigns has faded. The difficulties confronting union organizers in the United States are so obviously tied up with broader systemic problems that focusing on procedural failings may seem pedantic.

This study rejects such a view. To understand which systemic problems have the greatest impact on the growth and decline of the trade union movement, we need theory and models of where and how those problems interact with the union-organizing process. This will require an extended institutional model of process, one that includes successively earlier and later stages. As this study shows, such work will raise new questions even as it offers answers to old ones. By assembling national data for a larger portion of the organizing process than has heretofore been susceptible to close examination, by accounting for the endogeneity that characterizes choice-based selection models (Ben-Akiva et al. 1997), and by demonstrating sequential, cumulative effects over the course of that process, this study takes the first step in that direction.

Future research could move forward on three fronts. First, of course, more controls could be added. The goal of doing so would not be to increase the share of total variance explained as much as it would be to judge whether competing "determinants," such as national union characteristics and individual organizers' tactics, have different effects at different points in the process.

Second, the scope of the process could be broadened. For example, this paper does not model the card drive, on which no systematic data are collected. While the card drive is beyond the purview of the NLRB, individual unions often have records of their abortive organizing drives. These records could be appended to the main dataset, resulting in a subset of data containing information for the earliest organizing stage. We should, in any event, be wary of drawing a simple dichotomy between "formal,"NLRB-supervised and -certified organizing drives and "informal" ones. Even the "formal" drives have an informal component-the card drive-that is poorly documented and researched. "Informal" voluntary-recognition drives, in turn, may be more common after formal organizing drives have failed. For example, are ULP charges in an earlier period associated with 
corporate campaigns and neutrality agreements in a later period? The basic logic of extending the scope of the process remains the same here, and suggests a way to model shifts from one type of organizing effort to another.

Third, measures of institutional stability or decline could be added to the data. If we think that union decline results in part from larger transformations in the economic, legal, or regulatory environment, then we should be able to hypothesize both whether a particular institutional change should affect organizing drives' prospects and at what point in the process the effects should be felt. This third front would have to be the hardest-fought, inasmuch as the theory and empirics are the least developed, but it holds the most potential for tying our theories of organizing success and failure into wider discussions of changes in the employment relationship (Osterman and Burton 2004; Powell 2001).

The decline of unionization may have implications beyond labor-management relations. Markets rely on a constellation of institutions, some informal but many formal and legal, to function (Polanyi 1944; Granovetter 1985; World Bank 2002). If union decline involves the erosion of other social and economic institutions, such as the rule of law or regulation in the economy, then that decline should be cause for broader worry. To the extent that the presence of ULP charges signals institutional erosion, a better understanding of exactly where they affect the organizing process will help us decide how concerned we should be.

\section{REFERENCES}

Ahlburg, Dennis A. 1984. "Majority Voting Rules and the Union Success Rate in National Labor Relations Board Representation Elections." Journal of Labor Research, Vol. 5, No. 3 (Summer), pp. 229-36.

Baron, James N., and William T. Bielby. 1980. "Bringing the Firm Back In: Stratification, Segmentation, and the Organization of Work." American Sociological Review, Vol. 45, No. 5 (October), pp. 737-65.

1985. "Organizational Barriers to Gender Equality: Sex Segregation of Jobs and Opportunities." In Alice S. Rossi, ed., Gender and the Life Course, pp. 233-51. New York: Aldine.

Ben-Akiva, Moshe, Daniel Mcfadden, Makato Abe, Ulf Böckenholt, Denis Bolduc, Dinesh Gopinath, Takayuki Morikawa, Venkatram Ramaswamy, Vithala Rao, David Revelt, and Dan Steinberg. 1997. "Modeling Methods for Discrete Choice Analysis." Marketing Letters, Vol. 8, No. 3, pp. 273-86.

Brudney, James J. 2005. "Contractual Approaches to Labor Organizing: Supplanting the Election Paradigm?" Labor and Employment Relations Association Series, Proceedings of the 57th Annual Meeting, pp. 106-13. Champaign, Ill.: Labor and Employment Relations Association.

Cohen, Larry, and Richard Hurd. 1998. "Fear, Conflict, and Union Organizing." In Kate Bronfenbrenner, Sheldon Friedman, Richard Hurd, Rudolph Oswald, and Ronald L. Seeber, eds., Organizing to Win: New Research on Union Strategies, pp. 181-96. Ithaca, N.Y.: ILR Press (an imprint of Cornell University Press).
Cooke, William N. 1983. "Determinants of the Outcomes of Union Certification Elections." Industrial and Labor Relations Review, Vol. 36, No. 3 (April), pp. 402-14.

Cooke, William N., and Frederick H. Gautschi, III. 1982. "Political Bias in NLRB Unfair Labor Practice Decisions." Industrial and Labor Relations Review, Vol. 35, No. 4 (July), pp. 539-49.

DiNardo, John, and David S. Lee. 2004. "Unionism in California and the United States: Using Representation Elections to Evaluate Their Impact on Business Establishments." In Ruth Milkman and Kim Voss, eds., Rebuilding Labor: Organizing and Organizers in the New Union Movement, Chap. 9, pp. 251-93. Ithaca, N.Y.: Cornell University Press.

Dunlop Commission. 1994. The Dunlop Commission on the Future of Worker-Management Relations: Final Report. Technical Report, U.S. Commission on the Future of Worker-Management Relations, Washington, D.C.

Farber, Henry S. 2001. "Union Success in Representation Elections: Why Does Unit Size Matter?” Industrial and Labor Relations Review, Vol. 54, No. 2 (January), pp. 329-48.

Fernandez, Roberto M., and Nancy Weinberg. 1997. "Sifting and Sorting: Personal Contacts and Hiring in a Retail Bank." American Sociological Review, Vol. 62, No. 6 (December), pp. 883-902.

Fiorito, Jack. 2003. "Union Organizing in the United States." In Gregor Gall, ed., Union Organizing: Campaigning for Trade Union Recognition, Chap. 11, pp. 191-210. Routledge Studies in Employment Relations. 
London: Routledge.

Fiorito, Jack, and Dennis P. Bozeman. 1997. "Fear and Loathing (and Bribery) in the Workplace: Worker Perceptions of Employer Responses to Union Organizing." Journal of Individual Employment Rights, Vol. 5, pp. $137-52$.

Flanagan, Robert J. 1989. "Compliance and Enforcement Decisions under the National Labor Relations Act." Journal of Labor Economics, Vol. 7, No. 3 (July), pp. 257-80.

2005. "Has Management Strangled U.S. Unions?" Journal of Labor Research, Vol. 26, No. 1 (Winter), pp. 33-63.

Freeman, Richard B. 2005. "What Do Unions Do? The 2004 M-Brane Stringtwister Edtion.” NBER Working Paper 11410, June; available online at http://www. nber.org/papers/w11410.

Freeman, Richard B., and Morris M. Kleiner. 1990. "Employer Behavior in the Face of Union Organizing Drives." Industrial and Labor Relations Review, Vol. 43, No. 4 (July), pp. 351-65.

Freeman, Richard, and James Medoff. 1984. What Do Unions Do? New York: Basic Books.

Freeman, Richard B., and Joel Rogers. 1999. What Workers Want. Ithaca, N.Y.: ILR Press (an imprint of Cornell University Press).

Gao, Chuanming, Kajal Lahiri, and Bernard Wixon. 2001. "Value of Sample Separation in a Sequential Probit Model: Another Look at SSA's Disability Determination Process." Mimeo, SUNY-Albany.

Getman, Julius G., Stephen B. Goldberg, and Jeanne B. Herman. 1976. Union Representation Elections: Law and Reality. New York: Russell Sage Foundation.

Granovetter, Mark. 1985. "Economic Action and Social Structure: The Problem of Embeddedness." American Journal of Sociology, Vol. 91, No. 3 (November), pp. 481-510.

Heneman, Herbert G., III, and Marcus H. Sandver. 1983. "Predicting the Outcome of Union Certification Elections: A Review of the Literature." Industrial and Labor Relations Review, Vol. 36, No. 4 (July), pp. 537-59.

Hirsch, Barry T., and David A. Macpherson. 2004. "Union Membership and Coverage Database from the Current Population Survey." Available online at http://unionstats.com.

Hoxie, Robert F. 1923. Trade Unionism in the United States, 2nd ed., pp. 31-77. New York: Russell \& Russell.

Hurd, Richard W., and Adrienne McElwain. 1988. "Organizing Clerical Workers: Determinants of Success." Industrial and Labor Relations Review, Vol. 41, No. 3 (April), pp. 360-73.

Kleiner, Morris M. 1984. "Unionism and Employer Discrimination: Analysis of 8(a) (3) Violations." Industrial Relations, Vol. 23, No. 2 (Summer), pp. 234-43.

Koeller, C. Timothy. 1992. "Employer Unfair Labor Practices and Union Organizing Activity: A Simultaneous Equation Model." Journal of Labor Research, Vol. 13, No. 2 (Spring), pp. 173-87.

Lahiri, Kajal, Denton R. Vaughan, and Bernard Wixon. 1995. "Modeling SSA's Sequential Disability Determination Process Using Matched SIPP Data." Social Security Bulletin, Vol. 58, No. 4, pp. 3-42.

Lawler, John J. 1984. "The Influence of Management
Consultants on the Outcome of Union Certification Elections." Industrial and Labor Relations Review, Vol. 38, No. 1 (October), pp. 38-51.

Lillard, Lee A., and Constantijn W.A. Panis. 2003. AML Multilevel Multiprocess Statistical Software, Version 2.0. Los Angeles: Econware.

Lillard, Lee A., and Robert J. Willis. 1994. "Intergenerational Educational Mobility: Effects of Family and State in Malaysia." Journal of Human Resources, Vol. 29, No. 4 (Fall), pp. 1126-66.

Lipset, Seymour Martin, Martin Trow, and James Coleman. 1956. Union Democracy: The Politics of the International Typographical Union. New York: Anchor.

Maranto, Cheryl L. 1988. "Corporate Characteristics and Union Organizing." Industrial Relations, Vol. 27, No. 3 (Summer), pp. 352-70.

McGuiness, Kenneth C., and Jeffrey A. Norris. 1986. How to Take a Case before the NLRB, 5 th ed. Washington, D.C.: Bureau of National Affairs, Inc.

Miller, Richard U., and George F. Leaming. 1962. "The Extent and Significance of Administrative Delays in the Processing of Union Representation Cases in Arizona." Arizona Review of Business and Public Administration, Vol. 2, No. 9, pp. 1-11.

Montgomery, B. Ruth. 1989. "The Influence of Attitudes and Normative Pressures on Voting Decisions in a Union Certification Election." Industrial and LaborRelations Review, Vol. 42, No. 2 (January), pp. 262-79.

Olson, Mancur. 1965. The Logic of Collective Action: Public Goods and the Theory of Groups. Cambridge, Mass.: Harvard University Press.

Osterman, Paul, and M. Diane Burton. 2004. "Ports and Ladders: The Nature and Relevance of Internal Labor Markets in a Changing World.” In Pamela Tolbert and Rosemary Batt, eds., Oxford Handbook on Work and Organization. Oxford: Oxford University Press.

Petersen, Trond. 1985. "A Comment on Presenting Results from Logit and Probit Models." American Sociological Review, Vol. 50, No. 1 (February), pp. 130-31.

Peterson, Richard B., Thomas W. Lee, and Barbara Finnegan. 1992. "Strategies and Tactics in Union Organizing Campaigns." Industrial Relations, Vol. 1, No. 2 (Spring), pp. 370-80.

Polanyi, Karl. 1944. The Great Transformation: The Political and Economic Origins of Our Time. New York: Rinehart.

Powell, Walter. 2001. "The Capitalist Firm in the 21st Century: Emerging Patterns." In Paul Dimaggio, ed., The Twenty-First Century Firm, pp. 34-68. Princeton: Princeton University Press.

Riddell, Chris. 2004. "Union Certification Success under Voting versus Card-Check Procedures: Evidence from British Columbia, 1978-1998.” Industrial and Labor Relations Review, Vol. 57, No. 4 (July), pp. 493-517.

Rose, Joseph B. 1972. "What Factors Influence Union Representation Elections?" Monthly Labor Review, Vol. 95, No. 10 (October), pp. 49-51.

Upchurch, Dawn M., Lee A. Lillard, and Constantijn W.A. Panis. 2002. "Nonmarital Childbearing: Influences of Education, Marriage, and Fertility." Demography, Vol. 39, No. 2, pp. 311-29.

Waelbroeck, Patrick. 2005. "Computational Issues in 
the Sequential Probit Model: A Monte Carlo Study." Computational Economics, Vol. 26, No. 2, pp. 141-61.

Wessels, Walter J. 1981. "Economic Effects of Right to Work Laws." Journal of Labor Research, Vol. 2, No. 1
(Winter), pp. 55-75.

World Bank. 2002. "Building Institutions for Markets: World Development Report, 2002.” Technical Report. Washington, D.C. 